\title{
Sherlock \\ e o palácio da memória
}

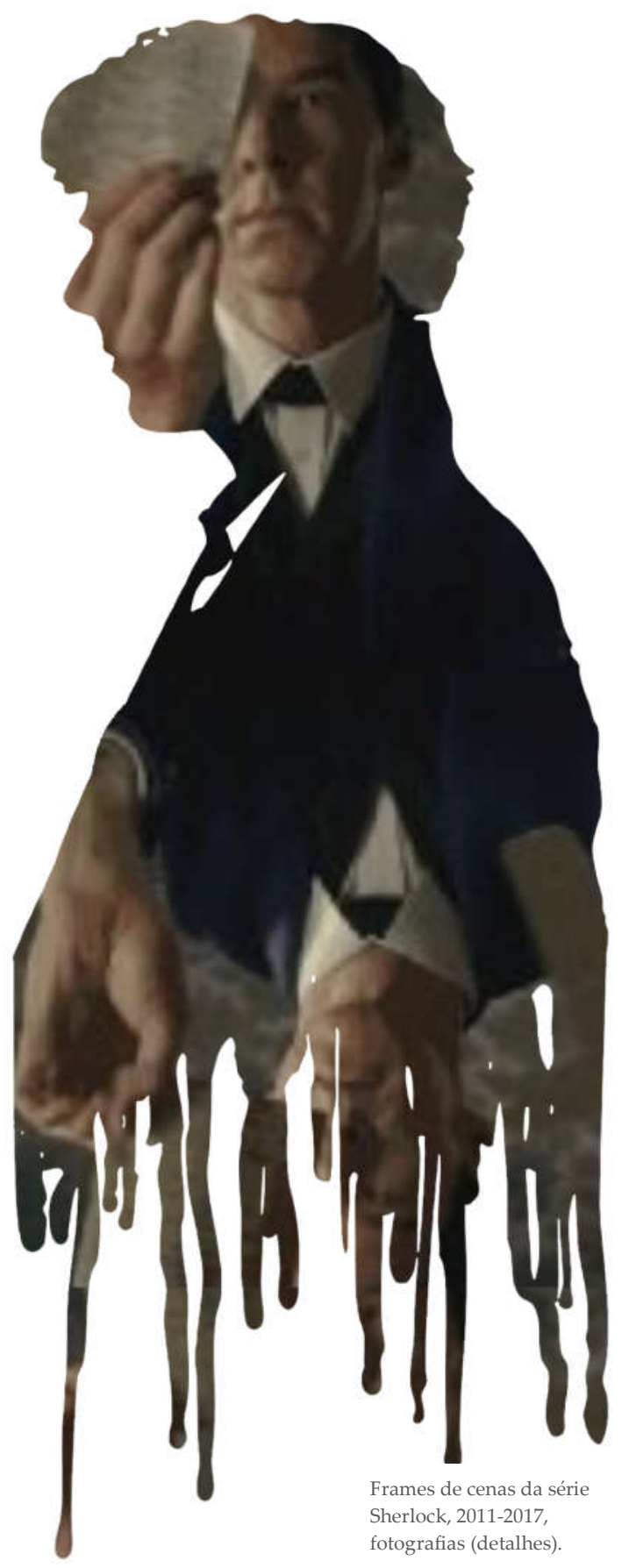

\section{Ana Carolina de Moura Delfim Maciel}

Doutora em História pela Universidade Estadual de Campinas (Unicamp). Coordenadora da Coordenadoria dos Centros e Núcleos Interdisciplinares de Pesquisa (Cocen) e professora do Programa de Pós-graduação em Multimeios da Unicamp. Autora, entre outros livros, de Yes nós temos bananas - cinema industrial paulista: a Companhia Cinematográfica Vera Cruz, atrizes de cinema e Eliane Lage, Brasil, anos 1950. São Paulo: Alameda, 2011. anacamaciel@gmail.com 
Sherlock e o palácio da memória

Sherlock and the memory palace

\section{Ana Carolina de Moura Delfim Maciel}

\section{RESUMO}

Neste artigo é analisado o sistema mnemônico, recentemente adaptado para a série da BBC Sherlock, sugestivamente referido como um "palácio da mente" ou "palácio da memória". Trata-se de uma espécie de exercício psíquico que permite a Holmes "revisitar" o seu passado. Nesse espaço mental, o protagonista consulta "arquivos" de dados (textos e imagens) que estão armazenados em sua mente em detalhes. Esse "poder" o leva a memorizar, relembrar e visualizar tudo. A técnica milenar do poeta grego Simônides de Ceos é aqui comparada com a virtualidade do processo de armazenamento nos "palácios virtuais" da atualidade, como a própria concepção de arquivo como forma de preservar e recriar a ideia de passado.

PALAVRAS-CHAVE: História; memória; audiovisual.

\begin{abstract}
In the present text the mnemonic system recently adapted for the $B B C$ series Sherlock, suggestively referred to as a "mind palace" or "memory palace" is analyzed. It is a sort of psychic exercise that allows Holmes to "revisit" his past. In this mental space the protagonist consults "archives" of data (texts and images) that are stored in his mind in its details. This "power" makes it possible for him to memorize, recall and visualize everything. The age-old technique from the Greek poet Simonides of Ceos is here compared with the virtuality of storage processes in the "virtual palaces" of nowadays, as the own idea of archiving as a way of preserving and recreating the idea of past.
\end{abstract}

KEYWORDS: History; memory; audiovisual.

A série televisiva Sherlock ${ }^{1}$ é uma produção da BBC londrina, disponível on demand, e, como o próprio nome sugere, é uma livre adaptação da obra de Conan Doyle. Trata-se de uma adaptação tão livre que opera uma licença poética ao abandonar o cenário original - de fins do século XIX e primórdios do século $X X$-, transpondo-o para os dias atuais, fazendo, assim, com que a trama transite entre os mundos contemporâneo e passado. ${ }^{2}$

Como não poderia deixar de ser, a série traz aventuras, e desventuras, do célebre protagonista que dá título à obra, sempre ao lado do fiel escudeiro, o "caro" Watson. Os 13 episódios das quatro temporadas são permeados por

${ }^{1}$ GATISS, Mark e MOFFAT, Steven (criadores). Sherlock. Produção de Sue Vertue e Elaine Cameron. Reino Unido, BBC, 2010-2017.

${ }^{2}$ Tendência interessante em séries são tais liberdades temporais. Ver a série televisiva Once upon a time, que inspira o filme homônimo. 
investigações, conflitos e, finalmente, pelo desfecho que resulta na solução de tramas, de mistérios e crimes. Gostaria de chamar a atenção - e, prometo, sem fazer spoiler para os que pretendem assisti-la - para um mecanismo de memória de Sherlock - sugestivamente denominado mind palace ou memory palace (palácio mental ou palácio da memória), uma espécie de exercício psíquico que possibilita ao detetive "revisitar" seu passado. E, por essa via, ele acessa "arquivos" (textos e imagens) ali armazenados. Tal "poder" lhe confere a faculdade - assim como ao personagem de um conto Jorge Luis Borges, "Funes, o memorioso" 3 - de tudo memorizar, tudo relembrar e tudo visualizar. Em um dos episódios, os personagens Watson e Stapleton comentam sobre esse dom de Sherlock:

John: Ah, é seu palácio mental. É uma técnica de memória. Uma espécie de mapa mental. Você traça um mapa com a locação - não necessita ser um lugar real - e daí você deposita memórias lá [...] teoricamente, você nunca pode esquecer de nada: tudo que você necessita fazer é encontrar seu caminho de volta.

Stapleton: Então, esse local imaginário pode ser qualquer coisa - uma casa ou rua.

John: Sim.

Stapleton: Mas ele [Sherlock] disse "palácio". Ele disse que era um palácio. ${ }^{4}$

Convém notar a ênfase de que esse local imaginário não poderia ser qualquer lugar ordinário, mas sim um palácio. Ou seja, o refúgio memorial de Sherlock é materializado num palácio: edificação que remete à proteção (muralhas, torres, fossos) e igualmente ao poder (econômico, político, bélico etc.). Dessa forma, por se tratar de um local imaginário e imaterial, ele é livre de parâmetros mundanos. E assim, nesse palácio mental, Sherlock aciona lembranças para dali estabelecer analogias, determinando um caminho investigativo, uma pesquisa em suas fontes armazenadas que culmina, inevitavelmente, com a solução de crimes.

O procedimento adotado por Sherlock, contudo, não é um recurso meramente ficcional, inventado pela trama televisiva. Memory palace é uma técnica mnemônica ancestral que tem sua origem relacionada ao poeta grego Simônides, remontando ao ano 477 a.C., e cuja prova de sua fabulosa memória ocorreu quando, durante um banquete, o teto desabou matando dezenas de pessoas. Simônides, que se ausentara momentaneamente do recinto, escapa ileso da tragédia, tornando-se então testemunha para o reconhecimento dos cadáveres, pois havia memorizado a posição de cada um dos convidados à mesa. Segundo Frances Yates, esse macabro episódio fez com que lhe fosse atribuída a invenção da arte da memória. ${ }^{5}$ Diz Yates: “Cícero enfatizava que a invenção da arte da memória por Simônides não radicava apenas na sua des-

\footnotetext{
${ }^{3}$ Personagem de conto homônimo de BORGES, Jorge Luis. Ficções. São Paulo: Companhia das Letras, 2007. 4 Trecho de Sherlock, op. cit. No original: John: Oh, his mind palace. It's a memory technique - a sort of mental map. You plot a map with a location - it doesn't have to be a real place - and then you deposit memories there that... Theoretically, you can never forget anything: all you have to do is find your way back to it. Stapleton: So this imaginary location can be anything - a house or a street. John: Yes. Stapleton: But he said "palace". He said it was a palace.

${ }^{5}$ Cf. YATES, Frances. A arte da memória. Campinas: Editora da Unicamp, 2007, p. 18.
} 
coberta da importância da ordem sequencial para a memória, mas também na de que o sentido da visão é o mais forte de todos os sentidos" ${ }^{6}$

O palácio de Sherlock, ativado por um mergulho no subconsciente, é onde ele consulta uma série de "documentos" ali arquivados. Em termos estéticos, esse momento é representado tendo como pano de fundo seu semblante absorto e concentrado, diante do qual projetam-se, em fantásticos efeitos de pós-produção, imagens: cartas, fotografias, cenas e personagens. A função desse palácio da memória, ou da mente, é o armazenamento e a preservação de dados, tal qual o design de um software.
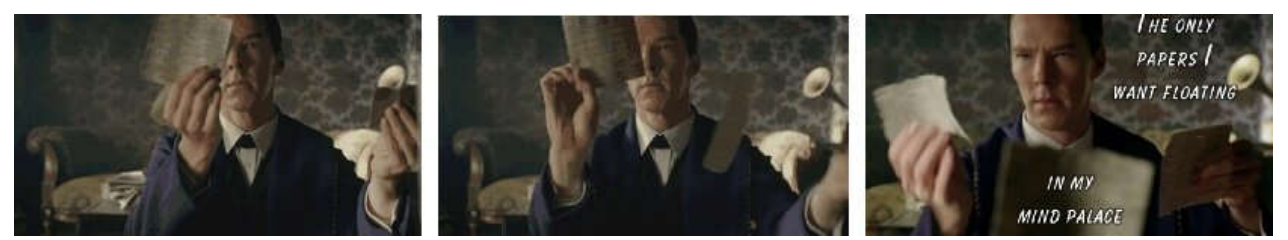

Figuras 1, 2 e 3. Frames de cenas da série Sherlock, fotografias (detalhes).

Nota-se que há uma sobreposição de imagens e que a produção em suporte fílmico amplia as camadas narrativas, conformando um palimpsesto que mescla processos mentais a processos audiovisuais, processos historiográficos a processos mnemônicos, e nessa confluência a importância de selecionar e sistematizar informações é patente, ultrapassando as fronteiras da história e adentrando em questões da semiótica, na medida em que, em última instância, o historiador está estudando linguagens e buscando decodificá-las e traduzi-las, para que façam sentindo dentro de determinado escopo narratológico.

Para que haja a construção narrativa, e novamente estabelecendo o paralelo com os recursos visuais, é necessário primeiro anunciar como pressuposto uma distinção entre figura e fundo. Ao narrar, pressupomos que nosso ouvinte conheça esses limites, caso contrário, precisaremos, antes, delimitálos. Ou seja, é necessário construir um lugar familiar de onde se conta. Assim, tratar sobre os limites entre memória e história leva-nos a questões mais gerais sobre o estar no mundo e sobre a constituição de si - e do outro - por meio da linguagem.

Nesse sentido, Sherlock narra primeiro para si mesmo a partir de fragmentos palpáveis, como bilhetes esparsos, manchas e partículas de pó para que eles concatenem sentido com informações previamente arquivadas em seu palácio mental, numa espécie de cruzamento e análise de fontes. Somente depois dessa operação, quando a informação já foi processada pelo personagem, é que a narrativa ganhará mais uma versão material, seja por meio da palavra verbalizada, escrita ou filmada, ou ainda num encontro de todas elas agregadas.

${ }^{6}$ Idem, ibidem, p. 20. 


\section{A materialidade dos palácios da memória}

Conectando Sherlock à nossa vida real, sugiro que a ideia de um palácio de armazenamento remeta diretamente ao espaço dos acervos e arquivos públicos como os palácios da memória do historiador, resguardadas as devidas proporções - talvez nem sempre tão suntuosos como desejaríamos, mas, sim, são nossos palácios. Dessa maneira, proponho meios de refletir sobre os arquivos extrapolando seu aspecto meramente depositário. Poderíamos nos perguntar, no entanto, como isso seria possível.

Creio que a resposta seria fomentando a produção de conhecimento por intermédio das fontes depositadas nesses lugares de memória; afinal, sabemos que os arquivos não produzem conhecimento, função atribuída aos pesquisadores com seus métodos de seleção e reflexão, a partir das fontes documentais. Porém, antes de formular uma questão norteadora, precisamos nos perguntar: qual é o "passado" com o qual nos deparamos nos arquivos? Valho-me da afirmação da teórica alemã Aleida Assmann: “O arquivo não é somente um repositório para documentos do passado, mas também um lugar onde o passado é construído e produzido". ${ }^{7}$

Do meu ponto de vista, o passado não se "resgata" em algum local obscuro para vir à luz. O passado se reconstrói em nosso tempo presente, muitas vezes acionado por vestígios materiais - textos, objetos, imagens. A fábula de Sherlock nos fascina (ou, no limite, me fascina) pela infinitude de sua memória, pela ausência de fronteiras desse palácio que se impõe como um universo tão amplo quanto inatingível, mas absolutamente ficcional. Na vida real, temos que nos contentar com fragmentos da memória e com a incompletude das fontes materiais.

Arquivos de tijolo e argamassa, ao contrário dos arquivos dos palácios imaginários, operam "meios materiais de arquivamento". ${ }^{8}$ Estamos num lugar de memória, de salvaguarda material de fronteiras delimitadas, cujos nexos advêm dos processos mentais que perpassam desde a curadoria e recepção de fontes, atingindo a produção intelectual gerada com base em sua análise. $\mathrm{O}$ arquivo salvaguarda, contudo seu maior sentido só se faz possível, inevitavelmente, pela produção de conhecimento proveniente das pesquisas em seus acervos.

Chamo a atenção para um componente fundamental denotador desse percurso mnemônico no palácio da memória: a noção de testemunha. A visita ao palácio - e a consulta às suas fontes - tira Sherlock de uma posição de mero observador. Não basta apresentar provas, pois, ao encontrá-las pairando em seu espaço mental, Sherlock torna-se testemunha dos eventos. Isso é intrínseco ao mito grego, ao qual me referi anteriormente, como originário do mind pala$c e$, em que Simônides, após o acidente, testemunha onde estava sentado cada um dos convidados. Assim, Sherlock vai para seu local secreto, acolhido em seu subconsciente, e dali regressa como testemunha. Ninguém questiona a veracidade de suas afirmações, nem mesmo a Scotland Yard, deixando implícito que há narradores pressupostos como legítimos.

${ }^{7}$ ASSMANN, Aleida. Espaços da recordação: formas e transformações da memória cultural. Campinas: Editora da Unicamp, 2011, p. 25.

${ }^{8}$ Idem. 
Noto que há nesses espaços mentais e, portanto, virtuais, algo de etéreo e ao mesmo tempo denso, como os hologramas ou como as nuvens virtuais que armazenam dados de forma aparentemente descolada dos impactos materiais, mas que têm uma alta taxa de consumo de água através das hidrelétricas que dão a energia necessária para que tais memórias sejam arquivadas ou da emissão de gás carbônico pelas termelétricas. ${ }^{9}$ Mais uma vez, o ofício do historiador esbarra em outros campos de estudo, agora beirando a física. Pergunto-me: o que é memória imaterial quando pensamos que memória é energia concentrada e que, portanto, a energia, em determinadas condições de pressão e de temperatura, poderá ter a densidade necessária para ganhar corpo? Tendo tal materialidade, que ruídos a memória emitirá? No campo da história, essas perguntas e inquietações não passam de devaneios, ainda que sirvam como estímulo para escavarmos novos e velhos arquivos, sopremos a poeira sobre os livros e documentos - essas, sim, partículas familiares a nós, historiadores - e sigamos desbravando palácios, perseguindo pegadas e rastros com nossos sentidos ativados - como os poetas - para conformarmos uma história que produza sentido.

Não raro, corremos o risco de projetar nossas vidas individuais em histórias coletivas; tendemos a ler a história do "outro" como se fosse a própria, e esse é o dilema do narrador, pois, como eu disse anteriormente, é preciso partir de um lugar familiar, um lugar comum (não banal) para dar novos voos ao nosso olhar e nossa escuta. Esse é um trabalho impossível de se fazer sozinho, porque transcende gerações e leva o mais complexo e impalpável elemento, tempo. De fato, o que estou propondo é que repensemos nossa prática continuamente, para reestruturar a historiografia como a conhecemos. Inevitavelmente, utilizamos métodos, importantes, admito, de produção e manutenção da história e da memória que desprezam, em alguma medida, determinadas formas de narrar. Analisamos eventos, datas, personalidades, documentos, fotografias, exaustivamente, buscamos ouvir as vozes dos arquivos. Mas que passado é esse que encontramos encarcerado em nossos palácios? Afinal, memória é algo passível de ser acondicionado? E as memórias vivas que deambulam nas ruas?

\section{Memória, testemunho, história: tríade controversa}

Além de Sherlock, outras obras ficcionais inspiraram-se no palácio da memória. Dentre elas destaco o livro Hannibal ${ }^{10}$, mote do filme Silêncio dos inocentes ${ }^{11}$, no qual encontramos uma descrição de como seria o palácio da memória: “O palácio de Hannibal Lecter é vasto, até mesmo para os parâmetros medievais. Traduzido para o mundo tangível, ele poderia rivalizar com o $\mathrm{Pa}-$ lácio Topkapi, em Istambul, pelo tamanho e pela complexidade. Mil quartos, quilômetros de corredores, centenas de fatos ligados a cada objeto de decora-

\footnotetext{
${ }^{9}$ Cf. A poluição da nuvem digital. Disponível em <https://super.abril.com.br/tecnologia/a-poluicao-danuvem-digital/>. Acesso em 21 out. 2020.

${ }^{10}$ HARRIS, Thomas. Hannibal. Rio de Janeiro: Best Bolso, 2015.

${ }^{11}$ Ver idem, O silêncio dos inocentes. Rio de Janeiro: Record, 2018.
} 
ção de cada quarto, uma pausa agradável aguardando o Dr. Lecter sempre que ele decide lá se refugiar". ${ }^{12}$

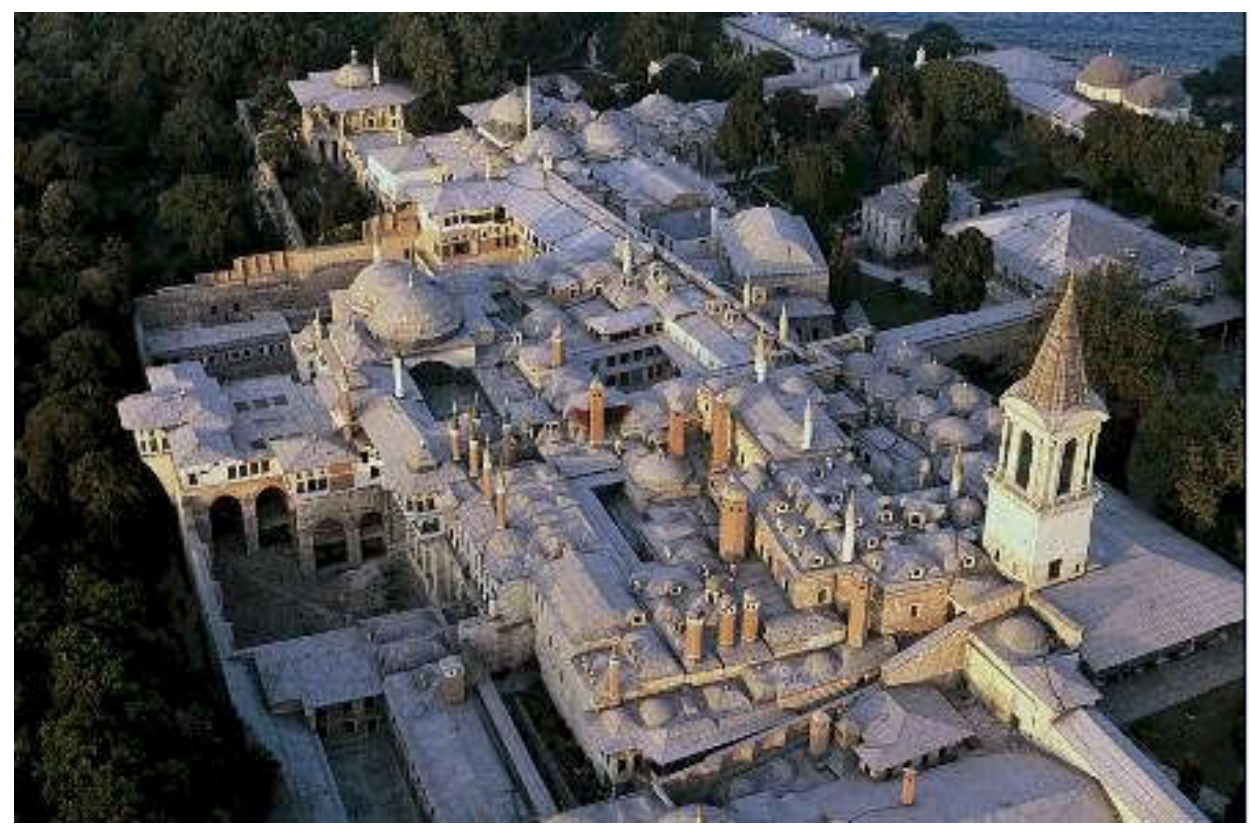

Figura 4. Palácio Topkapi, em Istambul, s./d., fotografia (detalhe).

Curioso notar que, embora o palácio do Dr. Lecter seja um lugar mental, a imagem à qual é comparado no trecho mencionado é bem real. Não é qualquer palácio, e sim um imenso, belíssimo e nababesco palácio. Ali, onde a memória pode navegar livremente, são os objetos materiais que a detêm. Esse cenário mental - onde qualquer analogia fantástica seria permitida - é pautado em parâmetros bastante materiais.

Julgo pertinente - ao praticar entrevistas no âmbito da história - refletir sobre a relação instaurada entre história, memória e testemunho, em que o narrador caminha por seu próprio palácio, revisita objetos condensados de informações e desperta memórias adormecidas, eventualmente provocadas por vozes externas, como a do historiador, que estimula que determinados cômodos sejam adentrados em detrimento de outros. Nesse sentido, penso que há, em certa medida, a manipulação dessas recordações, especialmente com o advento de novas tecnologias de registro, com as quais o historiador passa a produzir suas próprias fontes utilizando-se do registro audiovisual, numa tripla transposição: do palácio da memória para o memorioso, deste para o historiador, deste para o audiovisual. Aqui é importante frisar que, ainda que não haja edições no registro, este corresponde a um intervalo, um recorte, uma delimitação do momento da captação, ou seja, por mais sofistica-

\footnotetext{
12 MARTINEZ-CONDE, Susana. Neuroscience in fiction: Hannibal lecter's memory palace. Scientific America, New York, 2013. Disponível em <https://blogs.scientificamerican.com/illusion-chasers/hannibal-lecter/>. Acesso em 16 out. 2020. No original: Hannibal Lecter's palace is vast, even by medieval standards. Translated to the tangible world it would rival the Topkapi Palace in Istanbul for size and complexity. A thousand rooms, miles of corridors, hundreds of facts attached to each object furnishing each room, a pleasant respite awaiting Dr. Lecter whenever he chooses to retire there.
} 
dos que sejam os instrumentos e mais minucioso que seja o profissional, a narrativa será, sempre, cindida.

Dessa maneira, dizer que memória, testemunho e lembranças trazem para o presente a narração de eventos passados é uma equação simplista que mascara complexidades e tensões dessa inter-relação. Walter Benjamin no célebre texto "O narrador", escrito entre 1928 e 1935, apontou para uma profunda mudança na função do narrador e da transmissão oral, que paulatinamente perdem sua importância; algo que indica, consequentemente, a decadência da narrativa - considerada por Benjamin como uma forma artesanal da comunicação, e que não traz em si a função de transmissão "pura" do conteúdo dos fatos. Afinal, ainda segundo Benjamin, a narrativa carrega intrinsecamente "a marca do narrador": "a narrativa revelará sempre a marca do narrador, assim como a mão do artista é percebida, por exemplo, na obra de cerâmica". ${ }^{13}$

A questão da narrativa se impõe como algo de extrema importância em trabalhos sobre a memória e na discussão historiográfica. Com o gradativo desaparecimento de uma narração tradicional - algo magistralmente analisado por Benjamin -, surge uma outra forma de narração em que, nas palavras de Jean Marie Gagnebin, cabe ao "narrador um aspecto muito mais humilde, muito menos triunfante". ${ }^{14}$ Como conteúdo para essa narração, o narrador conta com as "sobras" que a história oficial, com seu rolo compressor, deixou para trás, quais sejam: o sofrimento, em grande parte impulsionado pelo trauma do pós-Segunda Guerra Mundial, e os personagens anônimos, esquecidos. Nesse sentido, o ato de lembrar e o ato de testemunhar sobre o vivido ganham força e legitimidade.

Desse modo, podemos dizer que o historiador conta com imagens multifacetadas: a história não obedece a critérios estanques, tampouco a comprovações. Na análise de Ginzburg, o ofício do historiador implica "destrinchar o entrelaçamento de verdadeiro, falso e fictício, que é a trama do nosso estar no mundo". ${ }^{15} \mathrm{E}$ a trama "do nosso estar no mundo" envolve os personagens que o povoam.

Ao longo do século XX foram publicados estudos de suma relevância para "libertar" o historiador da vã tarefa de depositário de datas, eventos e personagens. Valho-me novamente das reflexões benjaminianas, que conferem ao passado um aspecto multifacetado, fragmentado e que mostram que fazer história não é sinônimo de conhecer o passado "como de fato foi [...] significa apropriar-se de uma reminiscência, tal como ela relampeja no momento de um perigo". ${ }^{16}$ E o perigo está sempre situado no tempo presente.

Nos anos 1980, o historiador Pierre Nora defendeu uma oposição entre memória e história, sugerindo o desaparecimento da memória. Ele argumenta que foi a "aceleração da história" que impulsionou o crescimento de um interesse pela memória, num momento em que, paradoxalmente, passa-se a falar

\footnotetext{
13 BENJAMIN, Walter. O narrador. In: Textos escolhidos. São Paulo: Abril Cultural, 1975, p. 69.

${ }^{14}$ GAGNEBIN, Jean Marie. Memória, história, testemunho. In: BRESCIANI, Stella e NAXARA, Márcia (orgs.). Memória e (res)sentimento: indagações sobre uma questão sensível. Campinas: Editora da Unicamp, 2001, p. 90.

${ }^{15}$ GINZBURG, Carlo. O fio e os rastros. São Paulo: Companhia das Letras, 2007, p. 14

${ }^{16}$ BENJAMIN, Walter, op. cit., p. 222.
} 
"tanto de memória" porque ela não existiria mais. Discorrendo sobre dicotomias entre memória e história, diz Nora:

A história é a reconstrução sempre problemática e incompleta do que não existe mais. A memória é um fenômeno sempre atual, um elo vivido no eterno presente; a história, uma representação do passado. Porque é afetiva e mágica, a memória não se acomoda a detalhes que a confortam, ela se alimenta de lembranças vagas, telescópicas, globais ou flutuantes, particulares ou simbólicas, sensível a todas as transferências, cenas, censura ou projeções [...]. A memória se enraíza no concreto, no espaço, no gesto, na imagem, no objeto. A história só se liga às continuidades temporais, às evoluções e às relações das coisas. A memória é um absoluto e a história só conhece o relativo. ${ }^{17}$

Prosseguindo em sua análise, Nora considera que a memória foi tragada pela "história", não havendo mais "um homem-memória em si mesmo, mas um lugar de memória". Assim como Benjamin afirmou que não era necessário, para a história, conhecer o passado "como de fato foi", Jacy Alves de Seixas - ao analisar Proust - afirma que "a memória [...] constrói o real, muito mais do que o resgata", pois a memória "age 'tecendo' fios entre os seres, os lugares, os acontecimentos [...], mais do que recuperando-os, regatando-os ou descrevendo-os como 'realmente' aconteceram". Em suma, a memória "recria o real" e se impõe como detentora de um caráter "atualizador". ${ }^{18}$

É interessante pensar que no caminho de Swann ${ }^{19}$ as Madeleines são o passaporte para a infância do personagem e que, por extensão, são uma de nossas licenças para os caminhos da memória como leitores. O fluxo de consciência e as reminiscências, processos mentais, tornam-se figuras de estilo para o escritor e metáforas para o historiador, o qual coloca em xeque suas práticas continuamente, sabendo que também está inserido nesses processos mnemônicos e catalográficos. Por maior que seja a seriedade e o comprometimento do historiador em sua prática, é necessário admitir que são tênues os limites entre ficção e não ficção na história e em sua forma de expressão, qual seja, a narrativa por escrito, ou melhor, a historiografia. Podemos afirmar que, grosso modo, a história remete ao passado e o passado remete à memória. Oposições como objetividade versus subjetividade e história versus ficção pautam reflexões voltadas às relações entre história e memória, cujas gradações vêm ganhando mais matizes. Conforme abordei em outro texto, refuto a ideia de que a história e o audiovisual sejam espelhos da realidade ou do passado, porque, "de fato, não há, absolutamente, nenhum espelho", como sintetiza Siegfried Kracauer. ${ }^{20}$

Além do dilema sobre o que produz, o historiador é constantemente estimulado a inventariar informações e eventos de séculos acumulados em seu arquivo mental - mesmo que queiramos visitar cômodos mais amenos de nosso palácio, somos impelidos a recordar de eventos globalizantes e tomados

${ }_{17}$ NORA, Pierre. Entre memória e história: a problemática dos lugares. Projeto História, n. 10. São Paulo, 1993, p. 9.

18 SEIXAS, Jacy Alves de. Percursos de memórias em terras de história: problemáticas atuais. In: BRESCIANI, Stella e NAXARA, Márcia (orgs.), op. cit., p. 41 e 51.

${ }^{19}$ Cf. PROUST, Marcel. Em busca do tempo perdido: no caminho de Swann. São Paulo: Biblioteca Azul, 2006.

${ }^{20}$ Cf. MACIEL, Ana Carolina. História oral e o registro audiovisual: percursos e perspectivas. In: BARROSO, Vera Lucia Maciel (org.). História oral: democracia, direitos e diversidade. Porto Alegre: ISCMPA, 2018, p. 19. 
como marcantes para que a humanidade avançasse até aqui. Quantas vezes um historiador não viveu minutos de apreensão ao escutar o seguinte "desafio": "você que é historiador com certeza deve se lembrar...", sendo indagado sobre quando, onde e quais personagens estavam envolvidos em determinados acontecimentos. É quase um senso comum entre os leigos que os historiadores são detentores de uma boa memória - abrangente e ao mesmo tempo minuciosa. Trata-se de um exemplo cotidiano, dentre tantos outros, da controversa relação entre memória e história em que não há uma distinção entre ambas.

Essa concepção de história impregna o valor da memória como fonte histórica. Nessa perspectiva, o ato de lembrar, seus percursos e suas escolhas importam mais do que um relato "isento", se é que isso é possível, de um evento. Se, por um lado, a história tem sido "alforriada" de um passado positivista e cientificista, por outro, a memória, o esquecimento e o valor testemunhal passam a ser fenômenos de grande importância para uma valoração do indivíduo e do testemunho no fazer historiográfico.

Mas o conceito de memória é passível de complexas definições, e seu diálogo com a história não pode ser analisado sem levar em conta a complexidade dessa relação; porém, não são muitos os estudos historiográficos que vêm se voltando a um aprofundamento dessa problemática teórica, como aponta Jacy Alves de Seixas: "muito se fala e se pratica a memória histórica - o boom da história oral e das biografias e autobiografias é, nesse sentido, bastante expressivo -, mas pouquíssimo se reflete sobre ela". ${ }^{21}$

Nessa perspectiva, como destaca Seixas, "toda memória hoje em dia é uma memória exilada, que busca refúgio na história". ${ }^{22}$ Há ainda na atualidade outra linha de pensamento que pretendeu refletir sobre as relações entre memória e história. Trata-se de uma produção anglo-saxônica que parte de uma crítica à oposição entre elas, rumando para uma "apropriação da memória pela história", segundo Seixas ${ }^{23}$, numa tendência que leva a historiografia para "fora" da memória, numa postura vigilante e crítica. Contudo, nessa nova tendência não se discutem mecanismos de produção e reprodução da memória. O testemunho de um indivíduo, como afirma Paul Ricoeur, "constitui a estrutura fundamental de transição entre a memória e a história". Posicionando-se contra uma "tendência em abordar a memória a partir de suas deficiências" ${ }^{24}$, o autor considera que o único recurso para referenciar o passado é a memória.

A fonte testemunhal, na perspectiva de manter viva e de transmitir a memória, traz em si complexidades. Ora, lembranças não podem ser ingenuamente aceitas como um "atestado", como sendo algo isento de turvações da mente ou de uma tendência em se "ocultar", "mascarar" ou "hipervalorizar" determinadas vivências e/ou eventos. Não há relato inocente e imparcial. A narrativa parte de algum ponto em direção a outro por motivações e com intenções, sejam elas mais ou menos conscientes. Há que se considerar também os arquivos a que se tem acesso, podendo ocorrer de informações serem reite-

\footnotetext{
${ }^{21}$ SEIXAS, Jacy Alves de, op. cit., p. 43.

22 Idem.

${ }^{23} \mathrm{Idem}$.

${ }^{24}$ RICOEUR, Paul. A memória, a história, o esquecimento. Campinas: Editora da Unicamp, 2007, p. 38.
} 
radamente repetidas, por fontes ou documentos diferentes, de modo a criar certo roteiro, como indícios que deixamos pelo caminho, o qual, com o tempo, marca igualmente nosso caminhar, conformando alterações em nossas pegadas, como novas linhas nas digitais de memoriosos e Sherlocks frequentadores de acervos que somos.

$\mathrm{O}$ ato de lembrar deve ser analisado levando em conta sua perspectiva do presente; afinal, o ato de lembrar do passado ou de testemunhá-lo opera-se no aqui-agora, havendo necessariamente uma interferência em tal passado pelo simples fato dele ter sido transposto como narrativa para o tempo presente. Trata-se de um fenômeno complexo e profundo que tem uma camada inapreensível e efêmera, o agora, que no momento em que se pensou já transitou para outro nível da narrativa. Essa fugacidade do tempo e dos eventos é constantemente desafiada pelo historiador, que busca encadear e sistematizar fatos e personagens. Nesse sentido, o audiovisual, como ferramenta da narrativa histórica, não sobreposta à narrativa verbal escrita, mas aliada a ela, permitenos aproximar da simultaneidade dos acontecimentos, contribuindo para contar um mundo não linear. Em certa medida, fazer história é também ficcionalizar a realidade, como o mito teve - e tem - sua função na vida humana, para darmos conta do que não compreendemos.

Segundo François Hartog, em livro voltado para as evidências da história, nos anos 1980 ocorreu um progressivo aumento de interesse pela fonte testemunhal. Extrapolando molduras, o testemunho passou a ser considerado por meio de diversos suportes: "transcritos e reescritos, gravados e filmados". ${ }^{25}$ Esse impulsionamento se inseriu, em grande parte, numa preocupação de testemunhar o "trauma" do holocausto judeu. Passadas décadas do evento e com sobreviventes em idade avançada, operou-se uma valorização da memória e uma consequente corrida pelo registro de testemunhos. Nessa direção, a memória serve também como instrumento para "evitar" que uma catástrofe como tal se repita no futuro. À memória caberia, no limite, uma função messiânica.

Situando o lugar de minha fala, minha prática historiográfica é dedicada à captação de fontes, e ela, não por acaso, se apoia em reflexões direcionadas para as construções narrativas, as mais fecundas análises sobre o que envolve o fazer história em suporte audiovisual. Qual seria a roupagem da história, seja ela textual, oral ou audiovisual? Ainda que mudem e se alternem os suportes narrativos, estamos narrando, e é nesse caminho que reúno as indagações teóricas que me inspiram a refletir sobre questões concernentes à narrativa, à imagem e à história, independentemente de se tratar da história textual ou da história oral e audiovisual. Nessa ótica, lanço as seguintes indagações: (a) partindo da premissa de que não temos como tudo lembrar - e que tampouco temos um palácio onde tudo armazenar - onde nos refugiaremos?; (b) quantos palácios da memória serão necessários para salvaguardar o passado e alimentar os processos de memória?; (c) a começar pelos palácios existentes, como formular problemas, selecionar e refletir sobre eles, partindo das fontes ali depositadas?; (d) por que salvaguardar? O que salvaguardar?; (d) como articular práticas de guarda e de preservação com a produção de conhe-

${ }^{25}$ HARTOG, François. Évidence de l'histoire. Paris : École des Hautes Etudes en Sciences Sociales, 2006, p. 193. 
cimento?; (e) finalmente, como lidar com os fragmentos e com a finitude da matéria?

Chamo a atenção para o fato de que existem, na vida real, pessoas capazes de tudo se lembrar, ou seja, personagens de Borges em carne e osso. São cerca de 20 portadores de uma rara síndrome: "memória autobiográfica superdesenvolvida, ou hipertimesia". Esse é o caso do jovem inglês Aurelien, que assim definiu seu “dom memorial” para o jornal The Daily Mail: "É como se eu estivesse acessando rapidamente uma pasta arquivada [no meu cérebro] [...] Todas as datas têm fotos. É um processo visual, vejo uma sequência de imagens". ${ }^{26}$

Datas, fotos, pastas arquivadas... qualquer semelhança com nossos arquivos é mera coincidência. Na impossibilidade de encontrarmos refúgio em palácios da memória, temos que lidar, e nos contentar, com vestígios, rastros, farrapos. Nós, pesquisadores de arquivos, partimos em busca de nossas fontes e nos deparamos com fragmentos de toda sorte. Por outro lado, pensando num local - tão desejado quanto improvável - onde preservaríamos toda a memória do mundo, lá encontraríamos as fontes da memória e as traríamos para a superfície. Mas de que nos serviria isso? Sequer em nosso mundo cotidiano, em nossas vidas comezinhas, detemos de uma memória fiel.

Algo digno de nota na contemporaneidade é a crescente virtualidade dos processos de armazenamento, digitalizando e depositando documentos em "palácios virtuais", colocando em curso uma transformação na própria noção de arquivo. Será que nossos palácios de papel serão levados pela correnteza? Como alerta Assmann, as máquinas de processamento vêm "substituindo os metros de prateleiras com pastas e caixas sobre os quais a poeira dos séculos se assenta". ${ }^{27}$ De acordo com a autora, num futuro não muito longínquo, "a era digital vai descobrir novas formas para o arquivamento de informação e vai arquivar o próprio arquivo como um memorial obsoleto". ${ }^{28}$

Será que o palácio da memória concebido como uma viagem ao subconsciente é o prenúncio de uma nova era, em que será possível inserirmos em nossas mentes nanochips memoriais, nos quais pesquisaremos documentos e imagens? Suprindo nossa incapacidade física ou mental de tudo armazenar, seremos compelidos a acessar tais memórias artificiais? Demoliremos nossos palácios edificados e adentraremos em palácios mentais virtuais? Nosso destino será penetrar na arte da mnemotécnica e sermos todos Sherlock?

Assim, mais uma vez a ficção nos remete à vida real dos arquivos. Cada qual em seu palácio, no momento nos resta prosseguir, tendo em mente a incompletude da memória e a finitude das fontes documentais. No afã de imaginarmos um palácio onde tudo preservar, deparamo-nos, paradoxalmente, com uma realidade que caminha pari passu com a memória, ou seja, para o inevitável esquecimento.

Artigo recebido em 23 de outubro de 2020. Aprovado em 15 de janeiro de 2021.

\footnotetext{
${ }^{26}$ Ver Conheça o jovem que nunca esquece nada de sua própria vida. BBC Brasil, 2012. Disponível em $<$ http://www.bbc.com/portuguese/noticias/2012/09/120924_memoria_autobiografica_pai.shtml>. Acesso em 27 set. 2020

${ }^{27}$ ASSMANN, Aleida, op. cit., p. 26.

${ }^{28}$ Idem.
} 